\title{
əUnderstanding Bjerknes Compensation in Meridional Heat Transports and the Role of Freshwater in a Warming Climate
}

\author{
QIANZI YANG, YingYing ZHAO, QIN Wen, JiE YaO, AND HAIJUN YANG \\ Laboratory for Climate and Ocean-Atmosphere Studies, and Department of Atmospheric and Oceanic Sciences, \\ School of Physics, Peking University, Beijing, China
}

(Manuscript received 30 August 2017, in final form 26 February 2018)

\begin{abstract}
The Bjerknes compensation (BJC) under global warming is studied using a simple box model and a coupled Earth system model. The BJC states the out-of-phase changes in the meridional atmosphere and ocean heat transports. Results suggest that the BJC can occur during the transient period of global warming. During the transient period, the sea ice melting in the high latitudes can cause a significant weakening of the Atlantic meridional overturning circulation (AMOC), resulting in a cooling in the North Atlantic. The meridional contrast of sea surface temperature would be enhanced, and this can eventually enhance the Hadley cell and storm-track activities in the Northern Hemisphere. Accompanied by changes in both ocean and atmosphere circulations, the northward ocean heat transport in the Atlantic is decreased while the northward atmosphere heat transport is increased, and the BJC occurs in the Northern Hemisphere. Once the freshwater influx into the North Atlantic Ocean stops, or the ocean even loses freshwater because of strong heating in the high latitudes, the AMOC would recover. Both the atmosphere and ocean heat transports would be enhanced, and they can eventually recover to the state of the control run, leading to the BJC to become invalid. The above processes are clearly demonstrated in the coupled model $\mathrm{CO}_{2}$ experiment. Since it is difficult to separate the freshwater effect from the heating effect in the coupled model, a simple box model is used to understand the BJC mechanism and freshwater's role under global warming. In a warming climate, the freshwater flux into the ocean can cool the global surface temperature, mitigating the temperature rise. Box model experiments indicate clearly that it is the freshwater flux into the North Atlantic that causes outof-phase changes in the atmosphere and ocean heat transports, which eventually plays a stabilizing role in global climate change.
\end{abstract}

\section{Introduction}

The fundamental mechanisms maintaining energy balance of Earth's climate system are climate feedback and meridional heat transport (MHT). The former, defined as the relationship between the net radiation flux at the top of the atmosphere (TOA) and surface temperature, determines the local net energy budget in the vertical direction. The latter redistributes the tropicalextratropical energy imbalance horizontally. The mean structure of MHT is well recognized (Trenberth and Caron 2001). The atmosphere and ocean can transport as much as $5.5 \mathrm{PW}\left(1 \mathrm{PW}=10^{15} \mathrm{~W}\right)$ energy poleward

D Denotes content that is immediately available upon publication as open access.

Corresponding author: Haijun Yang, hjyang@pku.edu.cn across $35^{\circ} \mathrm{N}$ and $35^{\circ} \mathrm{S}$. For the global average, the MHT vanishes and the climate feedback determines Earth's overall temperature. At the regional scale, both the climate feedback and MHT are important for determining the regional energy balance. Any energy change because of the climate feedback will result in a change in MHT. In fact, recent studies (Liu et al. 2016; Yang et al. 2016) revealed an intrinsic connection between the local climate feedback and MHT change.

The Bjerknes compensation (BJC) states the relationship between the relative changes in the atmosphere and ocean heat transports (Bjerknes 1964). The local climate feedback determines how the BJC occurs (Liu et al. 2016; Yang et al. 2016). If the local climate feedback is neutral, the changes in atmosphere heat

This article is licensed under a Creative Commons Attribution 4.0 license (http://creativecommons. org/licenses/by/4.0/). 
transport (AHT) and ocean heat transport (OHT) can perfectly compensate each other, which is the perfect BJC. However, the local climate feedback is usually not neutral; thus, there is no perfect BJC. Regardless of the spatial scale, the prerequisites for the BJC are conservation of global total energy and equilibrium in ocean heat storage, which implies that the BJC can only be valid on decadal and longer time scales (Zhao et al. 2016). The BJC can be thought of as an intrinsic coupled mode of the atmosphere-ocean system, establishing a clear connection between the ocean circulation and the energy balance at the TOA. Moreover, it can act as a critical negative feedback in the coupled system, helping to maintain a regional energy balance and Earth's overall climate stability (Yang et al. 2016).

The BJC has been studied extensively (e.g., North 1984; Shaffrey and Sutton 2006; Langen and Alexeev 2007; van der Swaluw et al. 2007; Kang et al. 2008, 2009; Vellinga and Wu 2008; Rose and Ferreira 2013; Cheng et al. 2013; Yang et al. 2013; Seo et al. 2014; Yang and Dai 2015; Liu et al. 2016). It can occur in internal climate variability and in climate responses to external forcing. Controversies exist regarding the fundamental mechanism of BJC, and there exist significant differences in terms of compensation structures. The BJC can be perfect either in the extratropics (Shaffrey and Sutton 2006; Cheng et al. 2013) or near the equator (Vellinga and $\mathrm{Wu}$ 2008). Recently, theoretical studies by Liu et al. (2016) and Yang et al. (2016) showed that the BJC is actually determined by the local climate feedback, and that different BJC behaviors in various modeling studies can all be attributed to different climate feedbacks. They revealed the fundamental mechanism of $\mathrm{BJC}$, and provided a unified explanation for different BJC behaviors in different studies.

This work is part of our series of studies on the BJC. Our previous studies examined the BJC under various situations through coupled model sensitivity experiments (Yang et al. 2013; Yang and Dai 2015; Dai et al. 2017; Zhao et al. 2016; Yang et al. 2017). When the coupled climate system is disturbed by wind perturbation (Yang and Dai 2015) or freshwater hosing (Yang et al. 2017), the BJC can work very well because the global total energy remains nearly unchanged in these situations, which is in good agreement with the theoretical prediction (Liu et al. 2016; Yang et al. 2016). The local climate feedback determines how the BJC occurs, regardless of different climate response patterns in different perturbation situations. In this work, we investigate the $\mathrm{BJC}$ under global warming. Whether or not the BJC would still occur is worth exploring carefully. In a warming climate, the Earth system gains additional energy because of the enhanced greenhouse effect, increasing the ocean heat content. These violate the prerequisite to the BJC occurrence (Bjerknes 1964). So, the question is: Would the BJC fail under global warming?

Our results from a coupled climate model experiment forced by doubled $\mathrm{CO}_{2}$ show that the BJC can still be valid to some extent, even during the transient period of global warming (Fig. 1). In a warming climate, the freshwater flux into the ocean resulting from the sea ice melting in the northern extratropical Atlantic can weaken the ocean thermohaline circulation, resulting in surface cooling in the North Atlantic. This is consistent with the recent study by Sévellec et al. (2017), which suggests that the observed Arctic sea ice decline may explain the slowdown of the Atlantic meridional overturning circulation (AMOC) and a persistent "warming hole" observed at subpolar latitudes. Our coupled model results further suggest that the sea ice melting can eventually cause the BJC. Detailed processes will be presented in section 3. An important implication of these results is that, under the present-day global warming, we may still expect that the BJC plays a stabilizing role in mitigating Earth's climate shift.

The role of freshwater in BJC is emphasized in this work. Since it is difficult to separate the freshwater effect from the heating effect in the coupled model $\mathrm{CO}_{2}$ experiment, a simple box model is used to understand the freshwater role in a warming climate. The box model has explicit thermohaline circulation dynamics and several important feedbacks between the thermohaline circulation and surface buoyancy forcing (Nakamura et al. 1994, hereafter NSM94; Marotzke and Stone 1995, hereafter MS95). We show that the BJC is valid during the transient period of global warming, because the change in ocean thermohaline is mainly attributed to freshwater perturbation instead of heating perturbation. The role of the AMOC in the BJC is examined in details. The relative contributions of freshwater and heating perturbations to the AMOC strength change are assessed.

This paper is organized as follows. The coupled climate model and box model are introduced in section 2 . Climate responses and the $\mathrm{BJC}$ in the $\mathrm{CO}_{2}$ experiment of the coupled climate model are analyzed in section 3 . Box model experiments are performed and analyzed in section 4. A summary and discussion are given in section 5 .

\section{Coupled models and experiments}

The Community Earth System Model (CESM) of the National Center for Atmospheric Research (NCAR) is 


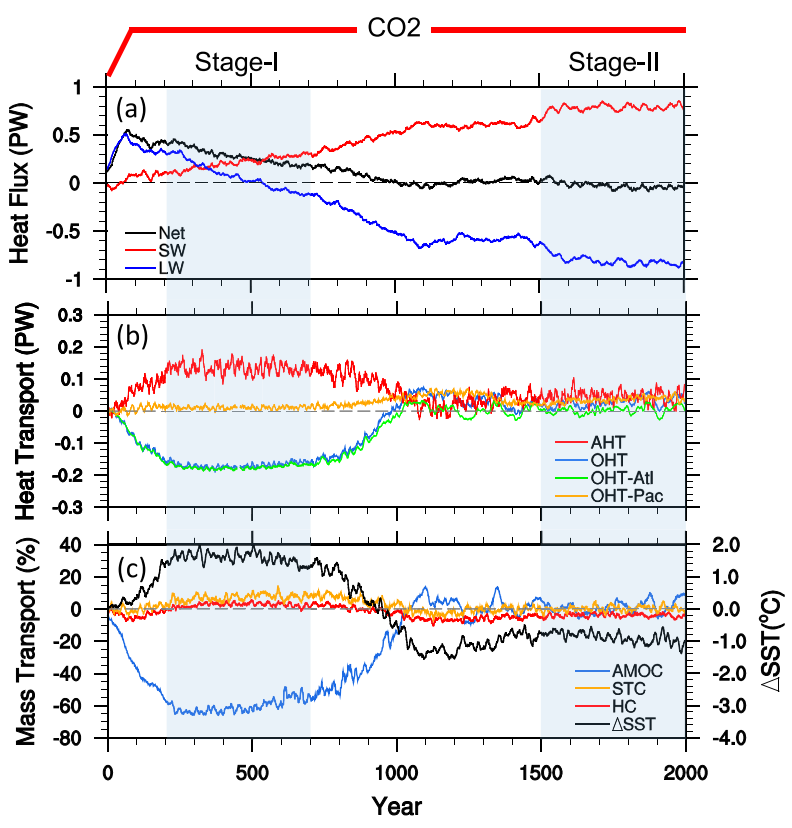

FIG. 1. Temporal changes of (a) globally integrated net radiation flux (black), net downward SW radiation (red), and net outgoing LW radiation (blue) at TOA (positive for downward anomaly; $\mathrm{W} \mathrm{m}^{-2}$ ), (b) AHT (red), global OHT (blue), Atlantic OHT (green), and Indo-Pacific OHT (orange) averaged over $30^{\circ}-70^{\circ} \mathrm{N}(\mathrm{PW})$, and (c) percentage changes of the AMOC (blue), the Indo-Pacific STC (orange), and the HC (red), and the meridional SST gradient change (black) under global warming. In (c), the AMOC index is defined as the maximum streamfunction in the range of $0^{\circ}-10^{\circ} \mathrm{C}$ over $20^{\circ}-70^{\circ} \mathrm{N}$ in the Atlantic. The IndoPacific STC is similarly defined, but in the range of $20^{\circ}-30^{\circ} \mathrm{C}$ over $0^{\circ}-30^{\circ} \mathrm{N}$. The $\mathrm{HC}$ index is defined as the maximum between 200 and $1000 \mathrm{hPa}$ over $0^{\circ}-30^{\circ} \mathrm{N}$. All indexes are normalized by their time-mean values in CTRL, which are 18,36 , and $92 \mathrm{~Sv}$, respectively. Here, $1 \mathrm{~Sv}=10^{6} \mathrm{~m}^{3} \mathrm{~s}^{-1}$ for the ocean and $1 \mathrm{~Sv}=10^{9} \mathrm{~kg} \mathrm{~s}^{-1}$ for the atmosphere. The SST gradient is defined as the SST difference between the tropics $\left(10^{\circ} \mathrm{S}-10^{\circ} \mathrm{N}\right)$ and extratropics $\left(50^{\circ}-70^{\circ} \mathrm{N}\right)$, and its scale is indicated by the $y$ axis at the right. These curves are smoothed with an 11-yr running mean. The red line at the top denotes the $\mathrm{CO}_{2}$ forcing.

used in this study. We used this model in our previous studies on the global energy balance (Dai et al. 2017; Yang et al. 2017). Here, we briefly review the model setup. CESM is a fully coupled global climate model that provides state-of-the-art simulations of Earth's past, present, and future climate. The version we use is CESM version 1.0. The model grid used in this study is designated T31_gx3v7. The atmosphere model is the Community Atmosphere Model, version 5 (CAM5; Park et al. 2014); it has 26 vertical levels, with the finite volume nominal resolution of $3.75^{\circ} \times 3.75^{\circ}$ in the horizontal. The land model is the Community Land Model, version 4 (CLM4; Lawrence et al. 2012); it has the same horizontal resolution as the CAM5. The ocean model is the Parallel Ocean Program, version 2 (POP2; Smith et al. 2010). The grid is designated gx3v7, which has a uniform $3.6^{\circ}$ spacing in the zonal direction and a varying spacing in the meridional direction. The meridional spacing is $0.6^{\circ}$ near the equator, gradually reaching a maximum of $3.4^{\circ}$ at $35^{\circ} \mathrm{N}$ and $35^{\circ} \mathrm{S}$ and decreasing poleward, and 60 levels in the vertical. The sea ice model is the Community Ice Code, version 4 (CICE4; Hunke and Lipscomb 2008), and it has the same horizontal grid as the POP2. Readers can refer to Dai et al. (2017) and Yang et al. (2017) for more details.

The CESM experiments analyzed in this study include a 3000-yr control run (CTRL) and a 2000-yr global warming run. The CTRL starts from a state of rest, as in Dai et al. (2017) and Yang et al. (2017). The $\mathrm{CO}_{2}$ concentration in CTRL is set to $285 \mathrm{ppm}$. The model climate reaches a quasi equilibrium after 1000 years of integration (Yang and Dai 2015). The global warming experiment starts from year 1000 of the CTRL, with the $\mathrm{CO}_{2}$ concentration increased by $1 \% \mathrm{yr}^{-1}$ for 70 years and held constant at the doubled level from year 71 to year 2000. This experiment is referred to as CESM-CO2 (Table 1). Two "equilibrium" stages are defined for later analysis (Fig. 1). Stage-I is from years 200 to 700 , representing the earlier equilibrium stage in global warming, during which the ocean and atmosphere circulations, as well as the meridional heat transports, all reach quasi-equilibrium states (Figs. 1b,c), while the net radiation flux at the TOA is still unbalanced (Fig. 1a). Stage-II is from years 1500 to 2000 , representing the later equilibrium stage in global warming, during which the net radiation flux at the TOA regains its balance (Fig. 1a) and Earth's climate shifts to another regime and settles down at the doubled $\mathrm{CO}_{2}$ level. Note that the AMOC almost recovers to the strength of CTRL (Fig. 1c). The climate changes in stage-I and stage-II are obtained by subtracting corresponding states in CTRL.

TABLE 1. List of experiments.

\begin{tabular}{llcll}
\hline \hline \multicolumn{1}{c}{ Model } & \multicolumn{1}{c}{ Experiment } & Length $(\mathrm{yr})$ & \multicolumn{1}{c}{ Description } & \multicolumn{1}{c}{ Acronym } \\
\hline CESM & $\mathrm{CO}_{2}$ & 2000 & From 1\% to double in 70 yr and 2 $\times \mathrm{CO}_{2}$ for 1930 yr. & CESM-CO2 \\
Box model & Freshwater & 2000 & Forced by extratropical SSS anomaly from CESM-CO2. & Box-FW \\
& Heating & 2000 & Forced by TOA net radiation flux from CESM-CO2. & Box-CO2 \\
& Freshwater + heating & 2000 & Both Box-FW and Box-CO2. & Box-FW-CO2 \\
\hline
\end{tabular}




\section{Climate change in CESM-CO2 experiment}

\section{a. Compensation in meridional heat transports}

The change in radiation flux at the TOA, as expected, shows a net energy gain by the Earth system during the transient period of global warming (Fig. 1a). In the first 70 years when the $\mathrm{CO}_{2}$ concentration is increasing, Earth's energy gain is mainly due to the weakening outgoing longwave (LW) radiation (positive for downward anomaly and negative for upward anomaly), because of enhancing greenhouse effect. After the $\mathrm{CO}_{2}$ is doubled, the outgoing LW radiation increases gradually with the increasing surface temperature. Meanwhile, the incoming shortwave (SW) radiation also increases gradually because of decreasing polar albedo and global overall albedo (figures not shown) (Lawrence et al. 2012). Earth's energy gain is mainly attributed to the increase of SW radiation. The LW and SW radiation at the TOA finally reach a new balance after about 1000 years. Earth's climate then enters a new equilibrium state. Based on the evolution of the TOA radiation fluxes, we can roughly define the transient period of climate change under global warming as from years 1 to 1000 , and the equilibrium period as from years 1000 to 2000 .

The AHT change can compensate the OHT change by as much as $80 \%$ in the Northern Hemisphere $(\mathrm{NH})$ during stage-I of global warming (Figs. 1b), regardless of the significant change in the net radiation flux at the TOA (about $0.3 \mathrm{PW}$, Fig. 1a). The compensation rate here is simply defined as the absolute value of the AHT change divided by OHT change. There appears no compensation between AHT and OHT during stage-II of global warming (Fig. 1b), when Earth's climate reaches a new equilibrium state and both AHT and OHT are enhanced northward. Keep in mind that the changes shown in Fig. 1 are relative to the CTRL. The internal variabilities of AHT and OHT in stage-II of the CESM-CO2 themselves may still show compensation to some extent at the decadal and longer time scales, as suggested in Zhao et al. (2016). In this study, we focus only on AHT and OHT changes relative to those in CTRL, and would not discuss their own internal variabilities. Here, stage-I can also be considered as the earlier "quasi equilibrium" stage of global warming although it is still in the transient period of climate change, because the ocean and atmosphere circulations, as well as the AHT and OHT, remain stable for about 400 years (Figs. 1b,c). We use quotation marks on the word "equilibrium" for the convenience of later discussion. Stage-II is the real equilibrium stage of global warming since Earth's climate reaches a new equilibrium (Fig. 1). Figure $1 \mathrm{~b}$ shows that the AHT and OHT change nearly linearly in the first 200 years of global warming, remain in quasi equilibrium for about 500 years in stage-I, and then recover toward the state of CTRL in the later 300 years of the transient period (years 700-1000). During the entire transient period, the AHT and OHT compensate well with each other.

The temporal evolution of OHT is in good agreement with that of the AMOC (Figs. 1b,c). Actually, the decrease (increase) of northward OHT can be mainly attributed to the weakening (recovering) of the AMOC. In stage-I, the AMOC is weakened by as much as $60 \%$ [Fig. 1c; the mean strength of AMOC in CTRL is about $\left.18 \mathrm{~Sv}\left(1 \mathrm{~Sv}=10^{6} \mathrm{~m}^{3} \mathrm{~s}^{-1}\right)\right]$. Accordingly, the OHT in the Atlantic declines by about $40 \%$ (Fig. 1b; the peak Atlantic OHT in CTRL is about $0.5 \mathrm{PW}$ ). In contrast, the Indo-Pacific OHT is enhanced slightly in the NH. In stage-II, the AMOC is fully recovered (Fig. 1c), and the northward OHT in the Atlantic is enhanced accordingly (Fig. 1b). The Indo-Pacific OHT does not change too much.

The temporal evolution of AHT is in good agreement with that of the Hadley cell (HC; Fig. 1c). Our coupled model results also show a nearly linear relationship between the change in the Hadley cell's intensity and the change in meridional SST gradient at the decadal and longer time scales (Fig. 1c). In fact, the linear relationship between the meridional atmosphere mass (heat) transport and the meridional SST gradient was assumed in the 1960s (Budyko 1969). It states the simplest coupled atmosphere-ocean dynamics in the meridional direction. This Budyko-type relationship is widely recognized and used in simple energy balance models (e.g., North 1975; Lindzen and Farrell 1977; Stone and Yao 1990). In our coupled model, the linear relationships among changes in AMOC, OHT, AHT, and the meridional SST gradient are also clear (Fig. 2). The positive correlation between AMOC and OHT (Fig. 2a), the negative correlation between OHT and meridional SST gradient (Fig. 2b), and the positive correlation between meridional SST gradient and AHT (Fig. 2c) are all robust. The lag/lead correlations among them are also calculated using the first 1000 years' data from Figs. 1b,c. The peak correlation for all pairs occurs nearly at the zero lag (figure not shown).

In this study, the meridional SST gradient is defined as the difference between SST averaged over $10^{\circ} \mathrm{S}-10^{\circ} \mathrm{N}$ and that averaged over $50^{\circ}-70^{\circ} \mathrm{N}$. It is enhanced in stage-I, and weakened in stage-II (Fig. 1c). In stage-I, the enhanced meridional SST gradient in the $\mathrm{NH}$, on the one hand, drives a stronger Hadley cell in the tropics (Fig. 1c), and on the other hand, causes a stronger baroclinicity in the extratropical atmosphere, resulting in enhanced storm-track activities and thus the eddy AHT. 

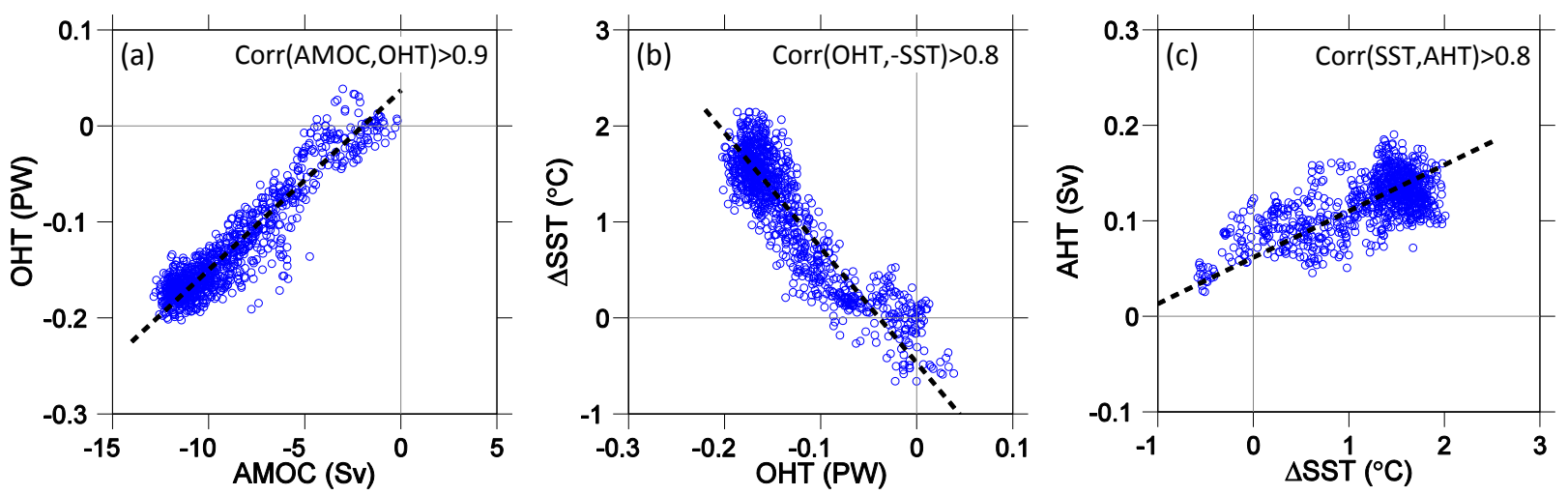

FIG. 2. Scatterplots showing the linear relationship between changes (a) in AMOC and OHT, (b) in OHT and meridional SST gradient, and (c) in meridional SST gradient and AHT. Data in years 1-1000 of Figs. 1b,c are used. Dashed black line shows the linear regression. Cross correlations among them are calculated within the maximum lag/lead $50 \mathrm{yr}$. In this range, correlations are all significant.

This is consistent with many previous studies (e.g., Shaffrey and Sutton 2006; Woollings et al. 2012). The enhanced storm-track activities are manifested in Fig. $3 \mathrm{~b}$, in which the total AHT change (red curve) is decomposed into changes due to the mean Hadley cell (dashed gray curve) and the eddy activities (solid gray curve). The former dominates in the tropics, while the latter dominates in the extratropics. These two aspects together contribute to the increase of the total AHT in the NH (Fig. 3b), compensating the decreased OHT (Fig. 3d). The stronger Hadley cell also causes a stronger subtropical cell (STC), enhancing the Indo-Pacific OHT (Fig. 3d), which in turn offsets partially the decreased Atlantic OHT (Fig. 3d). In stage-II, the meridional SST contrast becomes weaker than that in CTRL because of the polar amplification in SST, and the Hadley cell is weakened accordingly (Fig. 1c).

The BJC is still valid in a warming climate, although the global total energy is not conserved anymore, which violates the prerequisite for the BJC occurrence (Bjerknes 1964). From the viewpoint of global energy balance, the BJC would occur if the ocean heat content $(\mathrm{OHC})$ change were negligible when compared to the changes in AHT and OHT. Figure 3 summarizes the energy balance in stage-I of global warming. For a given latitude band (except in the polar region), the OHC increase (Fig. 3e) is only one-fifth of the energy gain at the TOA (Fig. 3a). The latter is also only onefifth of the changes in AHT and OHT (Figs. 3b-d). Small perturbation in TOA energy flux can cause strong changes in AHT and OHT. The regional oceanatmosphere energy balance has to rely on the out-ofphase changes in AHT and OHT. For example, in the extratropical $\mathrm{NH}\left(30^{\circ}-90^{\circ} \mathrm{N}\right)$, the ocean loses about $0.28 \mathrm{PW}$ heat because of the weakened AMOC (Fig. 3d). The total energy gain at the TOA is about
$0.15 \mathrm{PW}$ (Fig. 3a), in which 0.05 PW is used to increase the OHC (Fig. 3e). The extratropical oceanatmosphere system needs $0.18 \mathrm{PW}$ energy to maintain its balance; as a result, the northward AHT has to be enhanced.

\section{b. Sea surface temperature, salinity, and density changes}

Here, we examine the changes in horizontal distributions of sea surface salinity (SSS), SST, and sea surface density (SSD) in the two stages. In stage-I, we can see the cooling (i.e., the so-called warming hole; Sévellec et al. 2017) and freshening in the North Atlantic, as well as the weakening of deep-water formation resulting from the SSD change (Figs. $4 a-c)$. The warming hole in the subpolar North Atlantic (Fig. 4b) should have caused an increase in SSD. However, the SSD there decreased (Fig. 4c), suggesting the dominant role of the surface freshening (Fig. 4a). In stage-II, the freshening in the Arctic Ocean persists, while that south of $70^{\circ} \mathrm{N}$ stops because of the enhanced evaporation and lack of freshwater from the sea ice melting (figures are shown in section 3c). The SSS increase between $30^{\circ}$ and $70^{\circ} \mathrm{N}$ (Fig. 4d) should have caused an increase in SSD. However, the SSD there is decreased (Fig. 4f), suggesting the dominant role of strong surface warming in this stage (Fig. 4e), which manifests the most in the extratropics as a result of the sea ice-albedo positive feedback. We would like to emphasize that in different stages of global warming the surface buoyancy change is determined by different factors.

The importance of the freshwater perturbation to the changes in surface buoyance and thermohaline circulation can be further discerned by examining the differences between the two stages (stage-II minus stage-I). Although the strong surface warming reduces the 


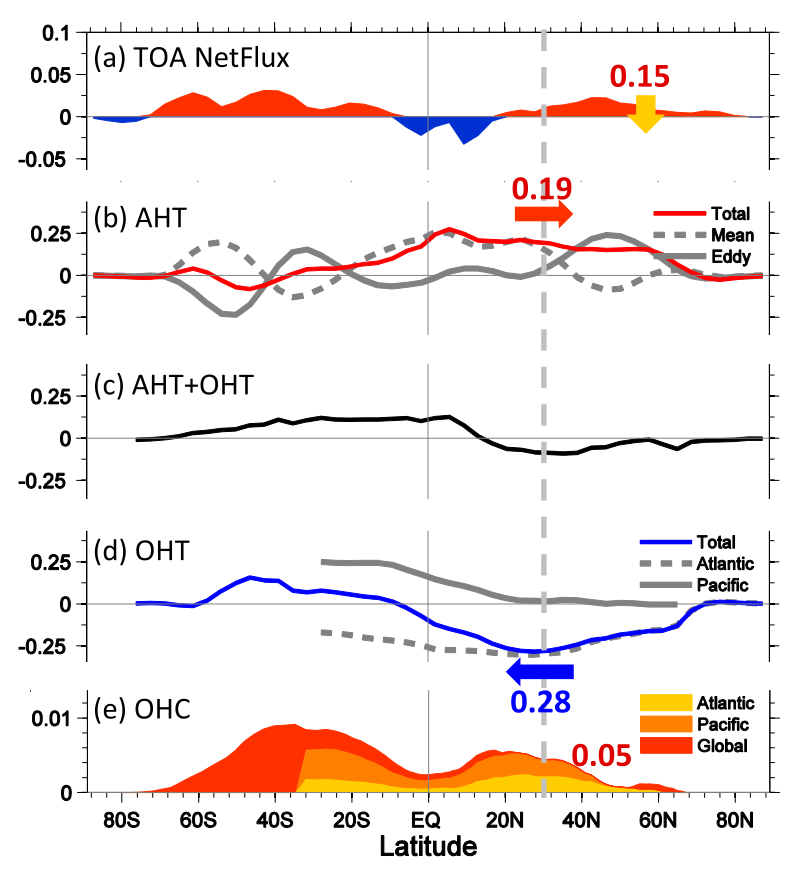

FIG. 3. Global energy change in the stage-I of global warming (PW): (a) net radiation flux change at the TOA [red (blue) represents net incoming (outgoing) energy]; (b) AHT change (red line represents total AHT change, solid gray line represents AHT change due to $\mathrm{HC}$ change, and dashed gray line represents eddy AHT change due to storm-track activities); (c) total MHT change; (d) OHT change (blue line represents the total OHT change in global ocean, solid gray line represents Indo-Pacific OHT change, and dashed gray line represents Atlantic OHT change); and (e) $\mathrm{OHC}$ change (red represents global $\mathrm{OHC}$ change, light red represents Pacific $\mathrm{OHC}$ change, and orange represents Atlantic OHC change). Dashed gray vertical line denotes $30^{\circ} \mathrm{N}$ and outlines the southern boundary of the extratropical box in which the energy gain at the TOA is $0.15 \mathrm{PW}$, and the OHC is increased by $0.05 \mathrm{PW}$. The AHT and OHT changes across $30^{\circ} \mathrm{N}$ are 0.19 and $-0.28 \mathrm{PW}$, respectively. These values have an error bar of $\pm 0.01 \mathrm{PW}$.

surface density (Figs. 4e,f), the SSD is indeed increased in the extratropical $\mathrm{NH}$ in stage-II when compared to that in stage-I (Fig. 4i). This is particularly clear in the subpolar North Atlantic, which is the main reason for the recovery of the AMOC in stage-II. Without the surface freshwater flux change (Fig. 4g), the polar amplification in SST [or surface air temperature (SAT)] could be much stronger (Fig. 4h) because the warming hole in Fig. $4 \mathrm{~b}$ is the consequence of the freshwater influx into the ocean (Sévellec et al. 2017). Moreover, whether or not the AMOC can recover in stage-II needs to be explored in depth. Here, we would like to conclude that the freshwater change under global warming can help to mitigate the global surface temperature rising (Vellinga and Wood 2002; Knutti et al. 2004; Drijfhout 2015), and act to stabilize the overall global climate to some extent by causing compensation changes in OHT and AHT. In section 4, the freshwater role will be investigated in a simple coupled box model, since it is difficult to separate the freshwater-only and heatingonly perturbations in a complex coupled model.

The pattern changes in the meridional overturning circulation are shown in Fig. 5 for reference. During stage-I of global warming, the northern branch of the Hadley cell is enhanced significantly in response to the enhanced meridional SST gradient in the NH (Fig. 5a). The wind-driven Indo-Pacific STC changes accordingly in response to the Hadley cell change (Fig. 5b). The AMOC is nearly shut down (Fig. 5c) because of the freshwater flux into the subpolar Atlantic Ocean. During stage-II of global warming, the patterns of the Hadley cell, the STC, and the AMOC are nearly recovered to the states in CTRL (Figs. 5d-f).

\section{c. Freshwater flux and its roles in MHT}

The surface buoyancy flux and ocean dynamics in the Atlantic appear to be the most critical players to the global OHT, AHT, meridional SST gradient, and the Hadley cell. In a warming climate, the AMOC decreases first, and then recovers because the freshwater flux change in the North Atlantic controls the SSS and thus the SSD (Fig. 6). Figure 6a shows clearly that the evolution of SSD (blue curve) in the North Atlantic is determined by that of SSS (red curve). Figure $6 \mathrm{~b}$ exhibits the linear relationship between the changes of SSS and SSD in the North Atlantic. Cross correlation between them shows a peak correlation occurs when the SSS leads the SSD by several months (figure not shown). Figure $6 \mathrm{c}$ shows a nearly linear relationship between the changes in AMOC and SSD. In the transient stage of global warming, the North Atlantic freshening (Figs. 4a and 6a) results from more freshwater entering the ocean (Fig. 7a, black curve), during which the sea ice melting (green) is the dominant factor. In the equilibrium stage of global warming, the North Atlantic becomes more saline (Figs. $4 \mathrm{~d}$ and $6 \mathrm{a}$ ) because there is no more sea ice melting to freshen the ocean surface (Fig. 7a, green) and the evaporation at the sea surface is enhanced significantly (blue). The freshwater change in the North Atlantic deep-water formation region $\left(40^{\circ}-60^{\circ} \mathrm{N}\right)$ controls the SSS, and thus the strength of the AMOC.

The sea ice melting and surface freshening in the Arctic Ocean are persistent during the whole period of global warming (Fig. 7b). However, the added freshwater appears to be confined in the Arctic Ocean and does not affect the lower latitudes (Figs. 8b,c,e,f). To better understand sea ice's role in the freshwater balance in the North Atlantic, both sea ice coverage and net freshwater flux are examined in Fig. 8. In CTRL, we see that the sea ice covers most of the Labrador Sea and the 

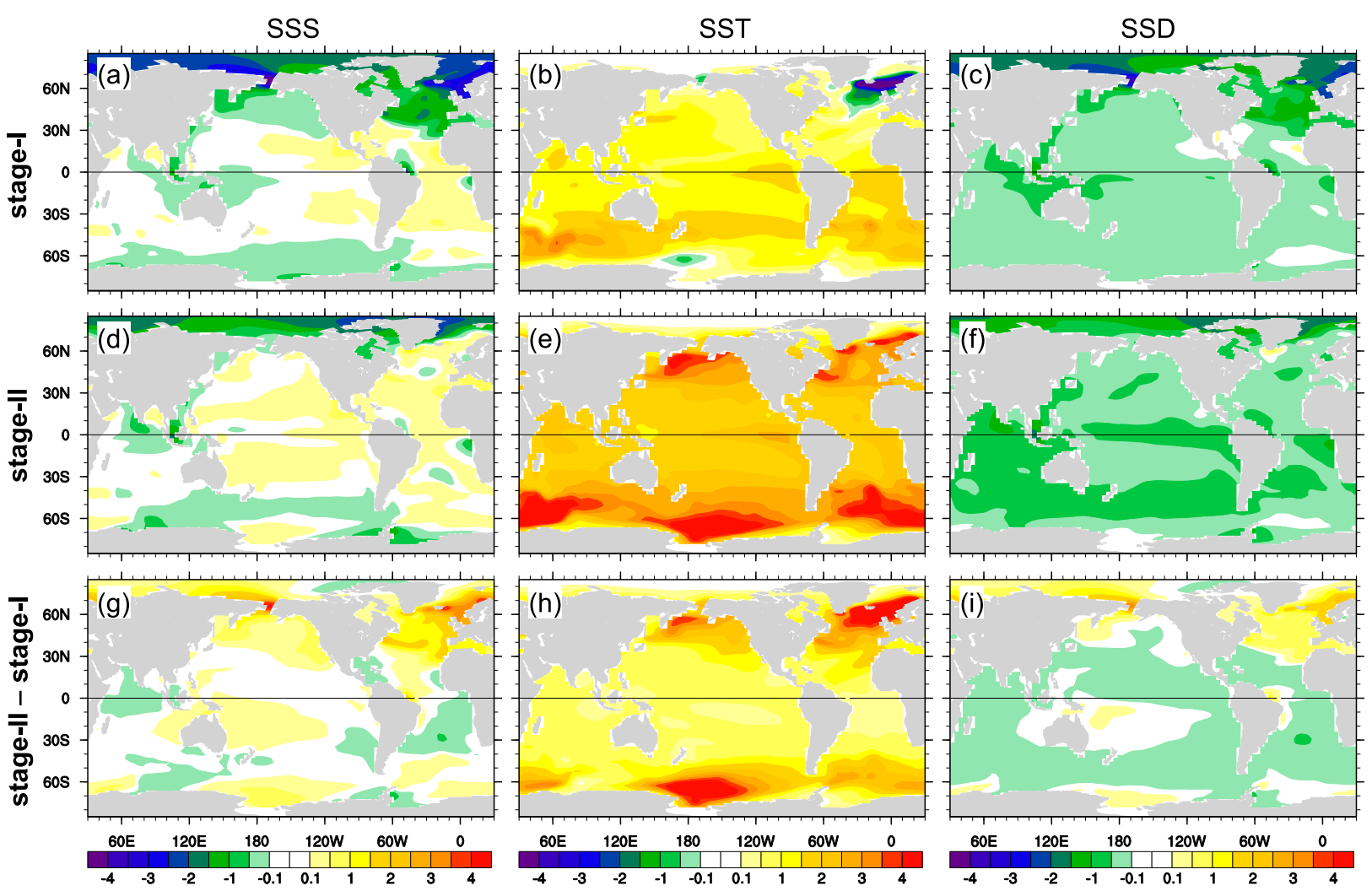

FIG. 4. Horizontal pattern changes in (a),(d) SSS (psu), (b),(e) SST $\left({ }^{\circ} \mathrm{C}\right)$, and (c),(f) SSD $\left(\mathrm{kg} \mathrm{m}^{-3}\right)$ under global warming. Shown are changes for (a)-(c) stage-I, (d)-(f) stage-II, and (g)-(i) the differences (stage-II minus stage-I). All panels use the same color bar, which uses variable intervals.

region north of $65^{\circ} \mathrm{N}$ in the North Atlantic (Fig. 8a). The sea ice margin is oriented along a southwest-northeast line from around $50^{\circ} \mathrm{N}$ in the west to about $75^{\circ} \mathrm{N}$ in the east coast of the Norwegian Sea (purple dashed curve in Fig. 8a). Iceland is located right in the middle of the sea ice margin line. The sea ice melting provides much of the freshwater into the ocean along the sea ice margin (Fig. 8d).

In stage-I of global warming, the sea ice declines significantly in the Labrador Sea and Arctic Ocean, as expected. The sea ice margin, however, expands southward slightly (solid curve in Figs. $8 \mathrm{~b}, \mathrm{e}$ ) beyond the south coast of Iceland because of strong surface cooling (Fig. 4b) and sea ice formation in this region (Fig. 8b). This situation is also studied in Jungclaus and Koenigk (2010) and Outten and Esau (2017). Accordingly, the net freshwater into the ocean in the sea ice formation region declines (Fig. 8e). In the deep-water formation region near $40^{\circ}-60^{\circ} \mathrm{N}$, including the Labrador Sea, the ocean continues to gain more freshwater (Fig. 8e). In stage-II of global warming, the sea ice is further reduced, and the sea ice margin finally retreats significantly (solid curve in Figs. 8c,f). There is almost no sea ice in most of the Labrador Sea and south of $70^{\circ} \mathrm{N}$ (Fig. 8c). The ocean south of $70^{\circ} \mathrm{N}$ becomes more saline again because of enhanced evaporation and lack of sea ice melting (Fig. 8f). The AMOC recovers, despite the polar amplification of global warming (Fig. 4e). The northward OHT is enhanced accordingly, which in turn contributes to the polar amplification. The persistent sea ice melting in the Arctic Ocean cannot freshen the ocean south of Iceland because of the strong anomalous northward surface current (Fig. 8f).

The major large-scale processes related to the $\mathrm{BJC}$ under global warming can be summarized as follows (Fig. 9). During the transient stage of global warming, the sea ice melting (Fig. 7a) in the subpolar region weakens the AMOC and OHT, resulting in a cooling in the North Atlantic and an intensified meridional SST gradient (Figs. 1c and 4b). The Hadley cell (Fig. 5a) in the tropics and the storm-track activities in the extratropics are enhanced (Fig. 3b). These two together lead to an increased AHT in the NH, compensating the decreased OHT. These processes are similar to those that occurred in the climate system perturbed by freshwater hosing in the North Atlantic (Yang et al. 2013, 2017), 

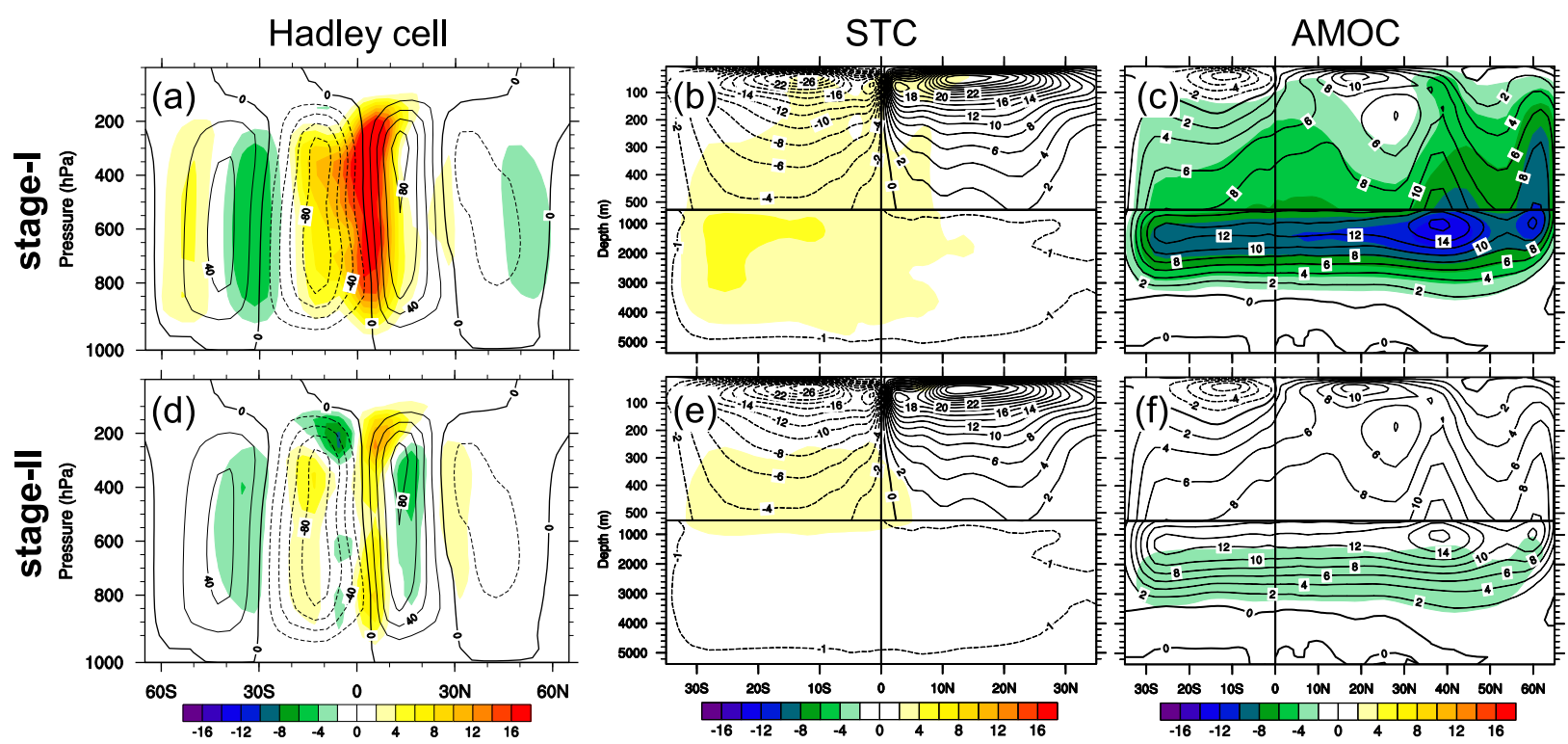

FIG. 5. Annual-mean patterns of (a) HC, (b) STC, and (c) AMOC (contours) and their changes in the stage-I of global warming (color shading) (Sv). (d)-(f) As in (a)-(c), but for stage-II.

particularly the dipole-like response in the SST during stage-I (Fig. 4b). During the equilibrium stage of global warming, freshwater flux into the North Atlantic diminishes significantly because sea ice melting is no longer available and strong evaporation occurs in the subpolar region. The AMOC recovers, and both the northward OHT and AHT return.

\section{Freshwater's role revealed by the box model}

Separating the effect of freshwater perturbation from that of heat perturbation is not easy in a complex coupled model, but can be easily done in a simple coupled box model. In this section, we use such a box model to understand the role of freshwater perturbation in the $\mathrm{BJC}$ in a warming climate. In our previous studies, we used the box model to investigate the BJC theoretically (Yang et al. 2016). The model has explicit thermohaline circulation dynamics, which can provide insights on how the BJC happens in a simple way. Detailed information about the box model can be found in the appendix.

Three experiments are conducted: Box-FW (adding freshwater only), Box-CO2 (doubling $\mathrm{CO}_{2}$ only) and Box-FW-CO2 (combined; Table 1). These experiments can simulate the "realistic" world in the coupled Earth system model, and provide us insight into the relative roles of freshwater and heat perturbations in the real world.

Based on Eqs. (A1) and (A2) in the appendix, the SW and LW radiation at the TOA and the climate feedbacks need to be given a priori. Figure 10 shows the temporal-latitude changes of the net radiation flux, the SW and LW radiation at the TOA, and the SAT in CESM-CO2, to be used as forcing for the box model. The net radiation flux change at the TOA shows a cooling
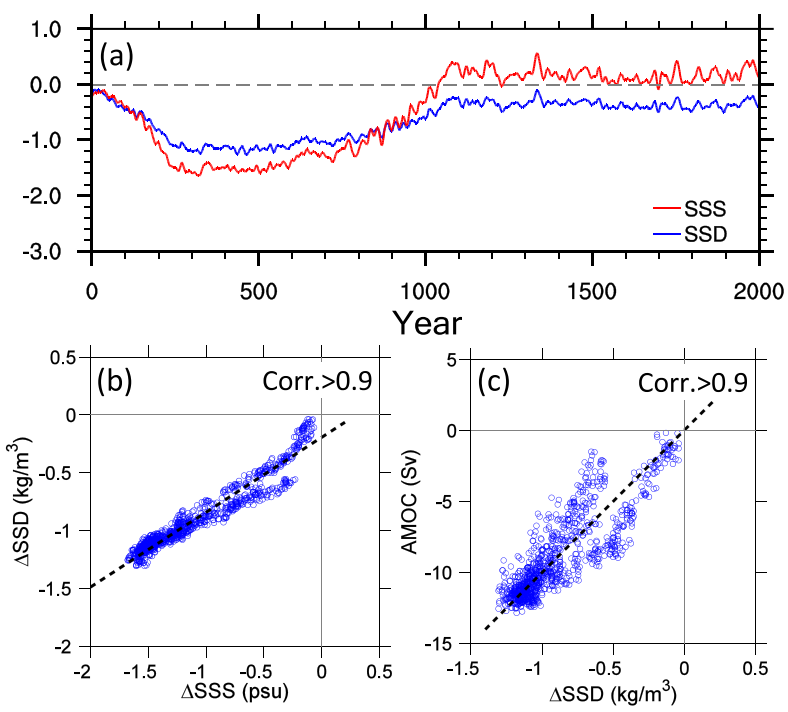

FIG. 6. (a) Temporal changes of SSS (red) and SSD (blue) averaged between $40^{\circ}$ and $60^{\circ} \mathrm{N}$ of the North Atlantic. The corresponding values in CTRL are subtracted. An 11-yr running mean is applied to the curve. The linear relationship (b) between changes in SSS and SSD and (c) between changes in SSD and AMOC, during years 1-1000 of global warming. Dashed black line shows the linear regression. Cross correlations among them are calculated within the maximum lag/lead $50 \mathrm{yr}$. In this range, correlations are all higher than 0.9 . 


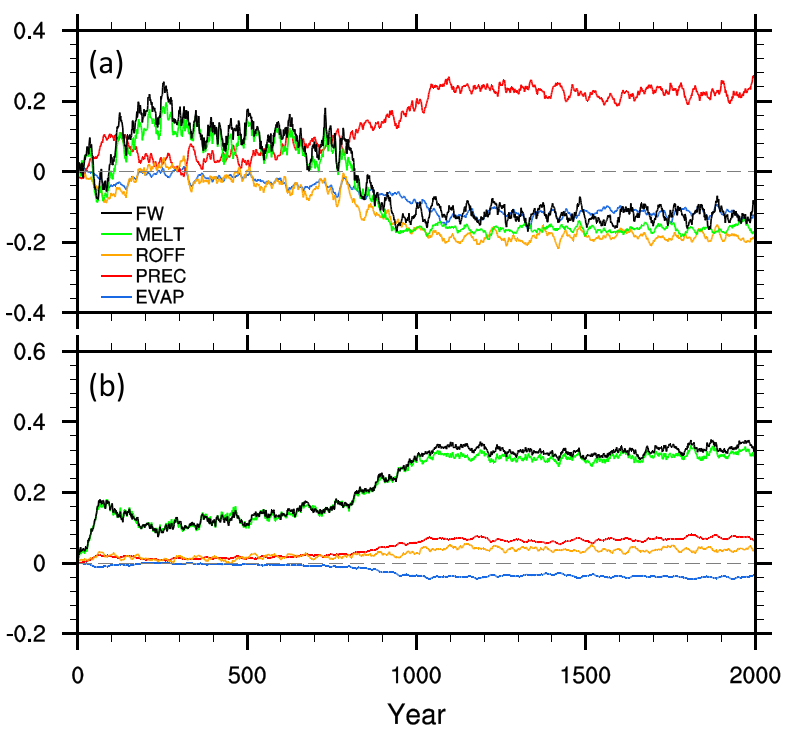

FIG. 7. (a) Temporal changes of surface freshwater flux averaged between $40^{\circ}$ and $60^{\circ} \mathrm{N}$ of the North Atlantic $\left(\mathrm{m} \mathrm{yr}^{-1}\right)$. Positive values represent freshwater entering the ocean. Black curve represents the net freshwater flux, red represents precipitation, blue represents evaporation, green represents sea ice melting, and orange represents river runoff. (b) As in (a), but the values are averaged in the Arctic Ocean. The corresponding values in CTRL are subtracted. An 11-yr running mean is applied to each curve.

effect in the tropics and polar region, and a warming effect in the midlatitudes (Fig. 10a). The tropical cooling effect is due to weakened net downward SW radiation, that is, more SW radiation being reflected back to the space (Fig. 10b). The polar cooling effect is due to more outgoing LW radiation (Fig. 10c) in response to the polar warming amplification (Fig. 10d). The midlatitude warming effect is due to enhanced SW radiative forcing, particularly over the Southern Ocean (Fig. 10b), which results from decreased low clouds and reduced sea ice.

It is important to see the varying climate feedbacks in the warming world (Figs. 10e,f). In the tropics, the net negative feedback is enhanced gradually with time (Fig. 10e, black curve), which is mainly attributed to the weakening of positive LW feedback (Fig. 10e, blue curve), caused by weakened LW cloud radiation forcing as a result of decreased high clouds (Yang et al. 2017). In the NH extratropics, the net positive feedback is weakening gradually with time (Fig. 10f, black curve), which is also attributed to the negative LW feedback (Fig. 10f, blue curve). We can see that the SW feedback changes only during the transient $\mathrm{CO}_{2}$ period and remains nearly stable once the $\mathrm{CO}_{2}$ is doubled. In general, Earth's climate in response to a doubled $\mathrm{CO}_{2}$ evolves slowly with an increasing negative climate feedback. This is critical for understanding the stability of Earth's climate under strong external forcing.
The role of freshwater in CESM-CO2 can be understood using the box model freshwater experiment Box-FW (Table 1), by forcing Eq. (A3) using the SSS anomaly shown in Fig. 6a. It is straightforward that the SSS anomaly in the extratropics determines the climate change in Box-FW: the freshening in the extratropics results in an intensified meridional SSS gradient ( $\Delta$ SSS $>0$; blue curve in Fig. 11b) and a weakening of the AMOC (Fig. 11b), which in turn reduces poleward OHT $(\Delta \mathrm{OHT}<0$; blue curve in Fig. 11c) and results in cooling (warming) in the extratropics (tropics) $\left(\Delta T_{1}<0\right.$ and $\Delta T_{2}>0$; Fig. 11a). This enhances the meridional SST contrast ( $\Delta$ SST $>0$; red curve in Fig. 11b). The atmosphere responds to the positive $\Delta$ SST with an enhanced AHT $(\Delta$ AHT $>0$; red curve in Fig. 11c). The AHT change compensates the OHT change very well (Fig. 11c). Here, the climate feedbacks $\left(-B_{1}=-0.7\right.$ and $B_{2}=0$ ) employed in Eqs. (A1) and (A2) are given as the LW feedbacks averaged over stage-II, representing a weak negative LW feedback in the extratropics and a neutral LW feedback in the tropics, respectively. The theoretical $\mathrm{BJC}$ rate based on Eq. (A5) is close to -1.0 , suggesting a nearly perfect compensation. The box model BJC shown in Fig. 11c $(\Delta \mathrm{AHT} / \Delta \mathrm{OHT} \sim-1)$ matches the theoretical value perfectly (Yang et al. 2016).

These processes are similar to what happened in the transient period of CESM-CO2 (Figs. 1b,c and 6). These processes were also investigated in depth in our previous studies (e.g., Liu et al. 2016; Yang et al. 2016). The dipole-like response of extratropical cooling $\left(\Delta T_{1}<0\right)$ and tropical warming $\left(\Delta T_{2}>0\right)$ in Fig. 11a is consistent with the results of many water-hosing experiments using coupled models (e.g., Manabe and Stouffer 1995; Stouffer et al. 2007). Here, we would like to emphasize the following. First, the BJC will be certain to occur under freshwater perturbation, and the degree of BJC is determined by the local climate feedbacks. Second, the salinity perturbation in the extratropics is critical to the circulation change, which determines the OHT change. This can be seen in Fig. 11c: The total OHT reduction (blue curve) is almost entirely due to the mass transport reduction (dashed blue curve), and the OHT change due to the enhanced temperature contrast is positive, opposite to the circulation change-caused OHT change, and, it is also negligible (green curve).

It is not straightforward whether the BJC would occur under heating-only perturbation. The BJC occurs, but only during the transient period of global warming (Fig. 11f). The role of radiation flux change caused by $\mathrm{CO}_{2}$ in the coupled climate model can also be understood via the coupled box model heating experiment Box-CO2 (Table 1), by directly replacing $A-B T$ in 

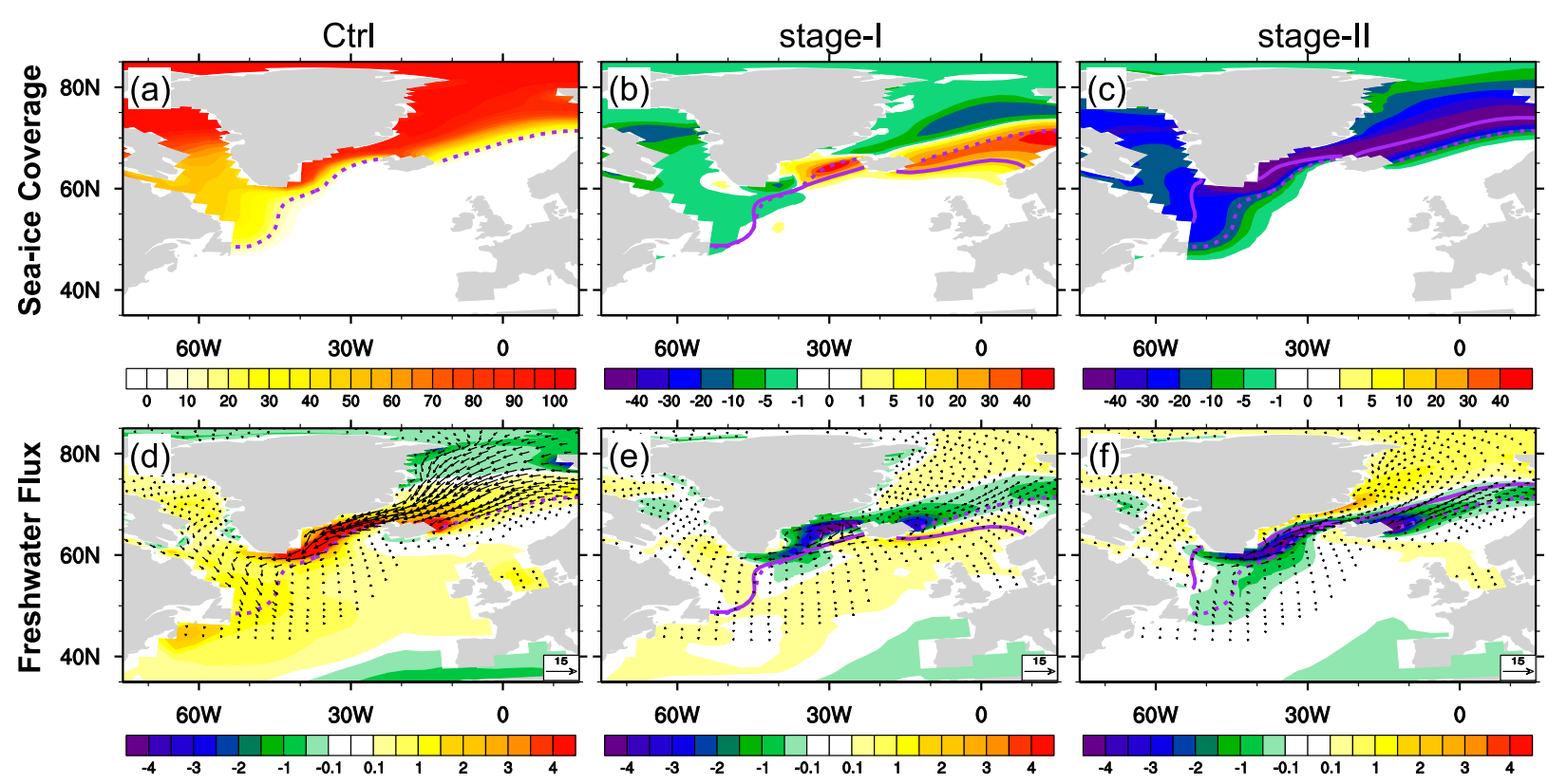

FIG. 8. (a) Mean sea ice coverage in CTRL and its change in (b) stage-I and (c) stage-II under global warming (\%). Positive values represent sea ice coverage increase. (d) Net surface freshwater flux in CTRL and its change in (e) stage-I and (f) stage-II under global warming $\left(\mathrm{m} \mathrm{yr}^{-1}\right)$. Positive values represent that the ocean gains freshwater. In (a)-(f), the dashed curve shows the sea ice margin in CTRL, which is defined as the $15 \%$ sea ice fraction in the Atlantic. The solid curves in (b),(e) and (c),(f) show the sea ice margin in stage-I and stage-II, respectively.

Eqs. (A1) and (A2) with the net radiation flux at the TOA averaged in the extratropics $\left(30^{\circ}-70^{\circ} \mathrm{N}\right)$ and tropics $\left(30^{\circ} \mathrm{S}-30^{\circ} \mathrm{N}\right)$, respectively. Note that in Box$\mathrm{CO} 2$, the climate feedbacks do not need to be given explicitly, since the net radiation flux at the TOA has already included the feedback effect and its temporal evolution (see Figs. 10e,f).

The heating-only perturbation causes almost no SSS change (Fig. 11d, green curve), and a negligible weakening of the AMOC (Fig. 11e, black curve). The global temperature rises significantly (Fig. 11d), similar to that which occurs in the equilibrium stage of CESM$\mathrm{CO} 2$ (Fig. 4e). The northward OHT is enhanced because of the enhanced stratification during the transient period of heating, since the upper ocean is warmed more than that below (blue and green curves, Fig. 11f). The polar amplification of SST is present (Fig. 11d, red curve) because of the northward advection of warm surface

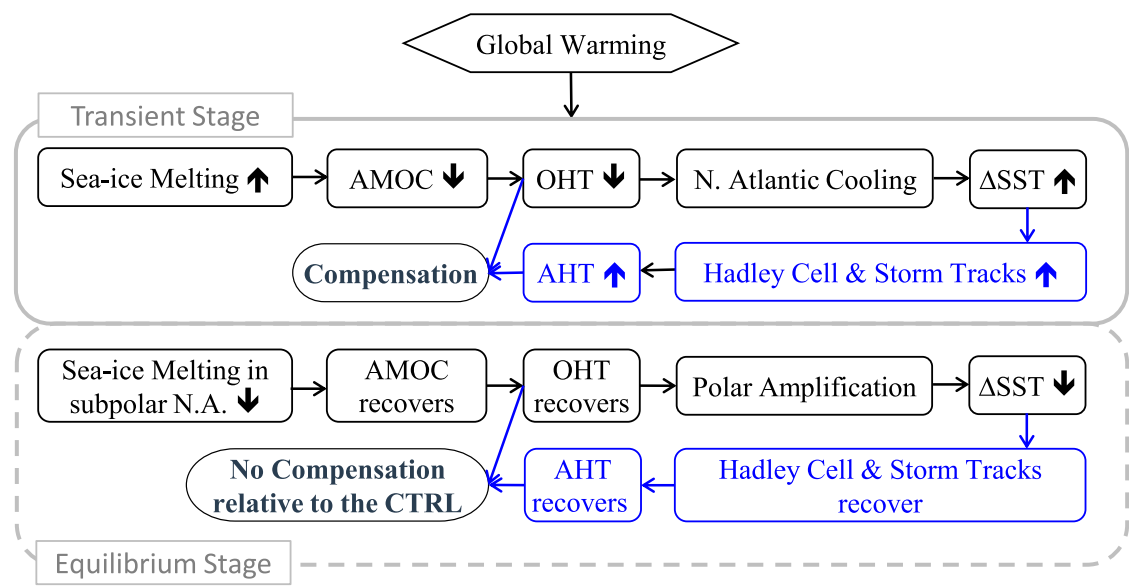

FIG. 9. Schematic diagram showing the main processes responsible for the compensation change between AHT and OHT under global warming. The upward (downward) arrows represent increase (decrease). N.A. denotes the North Atlantic, and $\Delta$ SST represents the northward SST gradient. 

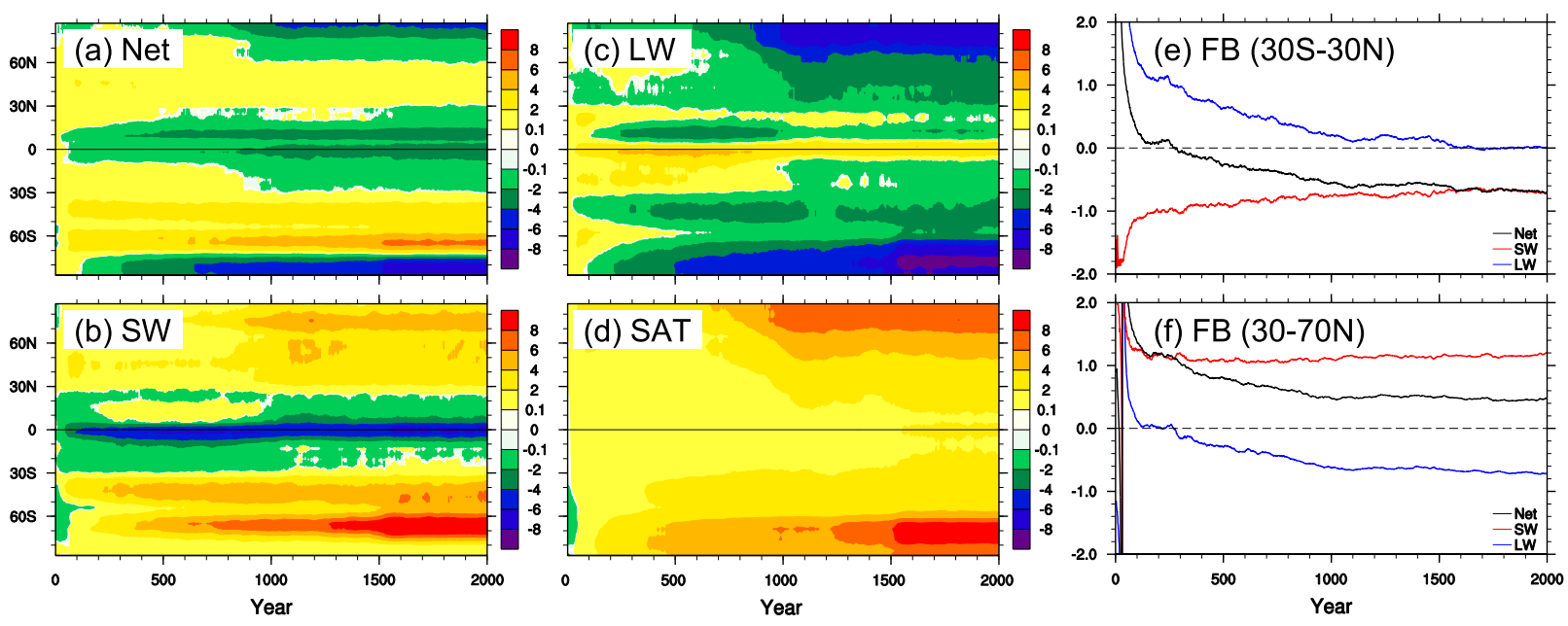

FIG. 10. Temporal-latitude changes of (a) the net radiation flux, (b) net downward SW radiation, (c) net outgoing LW radiation at the TOA $\left(\mathrm{W} \mathrm{m}^{-2}\right)$, and $(\mathrm{d}) \mathrm{SAT}\left({ }^{\circ} \mathrm{C}\right)$ in CESM-CO2. In (a)-(c), positive values represent downward anomaly. Please note the color bars do not use constant intervals. Temporal changes of local climate feedbacks $\left(\mathrm{W} \mathrm{m}^{-2}{ }^{\circ} \mathrm{C}^{-1}\right)$ averaged over the (e) tropics $\left(30^{\circ} \mathrm{S}-30^{\circ} \mathrm{N}\right)$ and (f) extratropics $\left(30^{\circ}-70^{\circ} \mathrm{N}\right)$. The red, blue, and black curves are for SW, LW, and net radiation feedbacks, respectively, which are obtained simply by dividing the radiation fluxes at the TOA by SAT.

water. The northward AHT is thus weakened slightly because of the polar amplification (Fig. 11f, red curve). The OHT change follows that in the stratification, and the AHT change follows that in the meridional SST gradient. They are clearly opposite during the transient period of global warming, but would have the same signs eventually because the global oceans' stratification would become nearly uniform. Therefore, the BJC can be valid during the transient period, but will become invalid in the equilibrium stage. An implication to the real climate is that the BJC may have been working very well since the preindustrial times; however, it can fail in the future if the greenhouses gases effect is enhanced beyond some critical value. This is one of our fundamental concerns about the present climate change.

The most critical difference between Box-CO2 and Box-FW is that the salinity change in Box- $\mathrm{CO} 2$ is negligible (blue curve, Fig. 11e), playing no role in the thermohaline dynamics, while the salinity change in Box-FW is significant (Fig. 11b), controlling the thermohaline circulation change. In Box-CO2, there is only one negative feedback between meridional SST gradient and thermohaline circulation. Both OHT and AHT are eventually determined by meridional SST gradient, so there would be no compensation eventually. In BoxFW, there are two feedbacks: the negative feedback between meridional SST gradient and AMOC, and the positive feedback between meridional SSS gradient and AMOC. The positive feedback determines the meridional SST pattern ultimately. The OHT is determined by the circulation, and the AHT is determined by the SST. They change oppositely and compensate each other. In addition, although there are opposite changes in OHT and AHT in Box-CO2 during the transient period of global warming (Fig. 11f), their magnitudes are too small and negligible when compared to those in Box-FW (Fig. 11c).

The combined effect of freshwater and radiation forcing is revealed in Box-FW-CO2. The climate change (Figs. $11 \mathrm{~g}-\mathrm{i}$ ) is nearly the linear combination of those in Box-FW and Box-CO2. The BJC is obvious in this situation because the freshwater effect dominates over the heating effect in determining the thermohaline circulation (Figs. 11h,i). The meridional SST gradient is enhanced (Fig. 11h), because the extratropical cooling induced by freshwater hosing dominates over the polar amplification of SST. The evolutions of meridional gradients of SST and SSS, the AMOC, AHT, and OHT (Figs. 11g-i) are all in good agreement with those in CESM-CO2 (Figs. 1b,c), particularly during the transient period of global warming. The box model experiments exhibit explicitly the dominant role of freshwater effect in determining the AMOC and MHT in the more realistic world of CESM, even under the doubled $\mathrm{CO}_{2}$ scenario. The freshwater hosing has a cooling effect on global temperature, offsets partially the rising temperature, and has a stabilizing effect on global climate change. Without the freshwater change, the global energy redistribution would be less predictable and the global temperature change would be much more radical.

\section{Conclusions and discussion}

We studied the BJC in a warming climate using a coupled Earth system model and a coupled box model. 

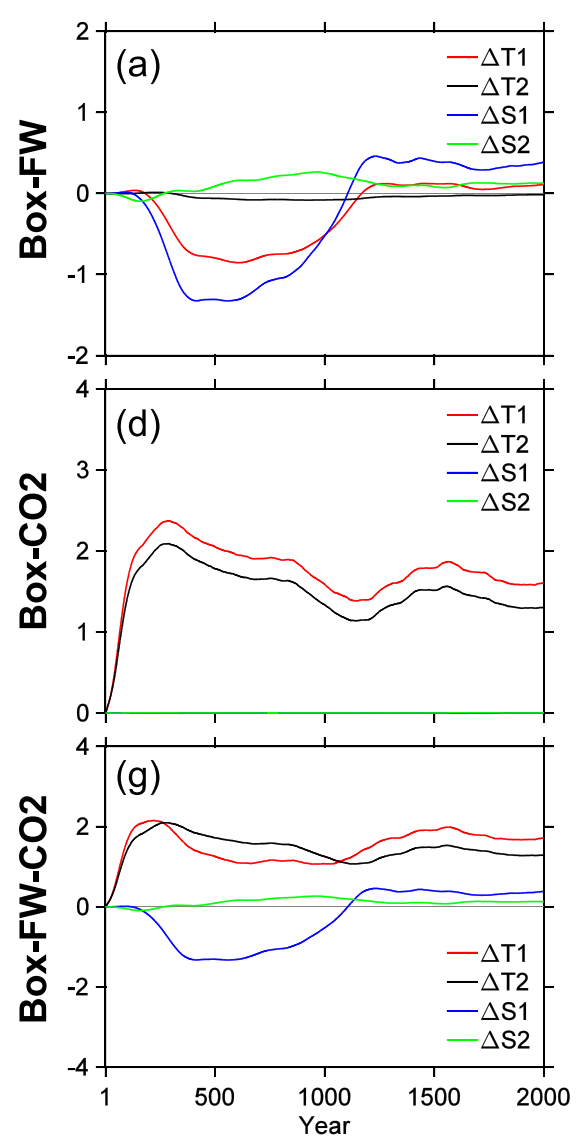
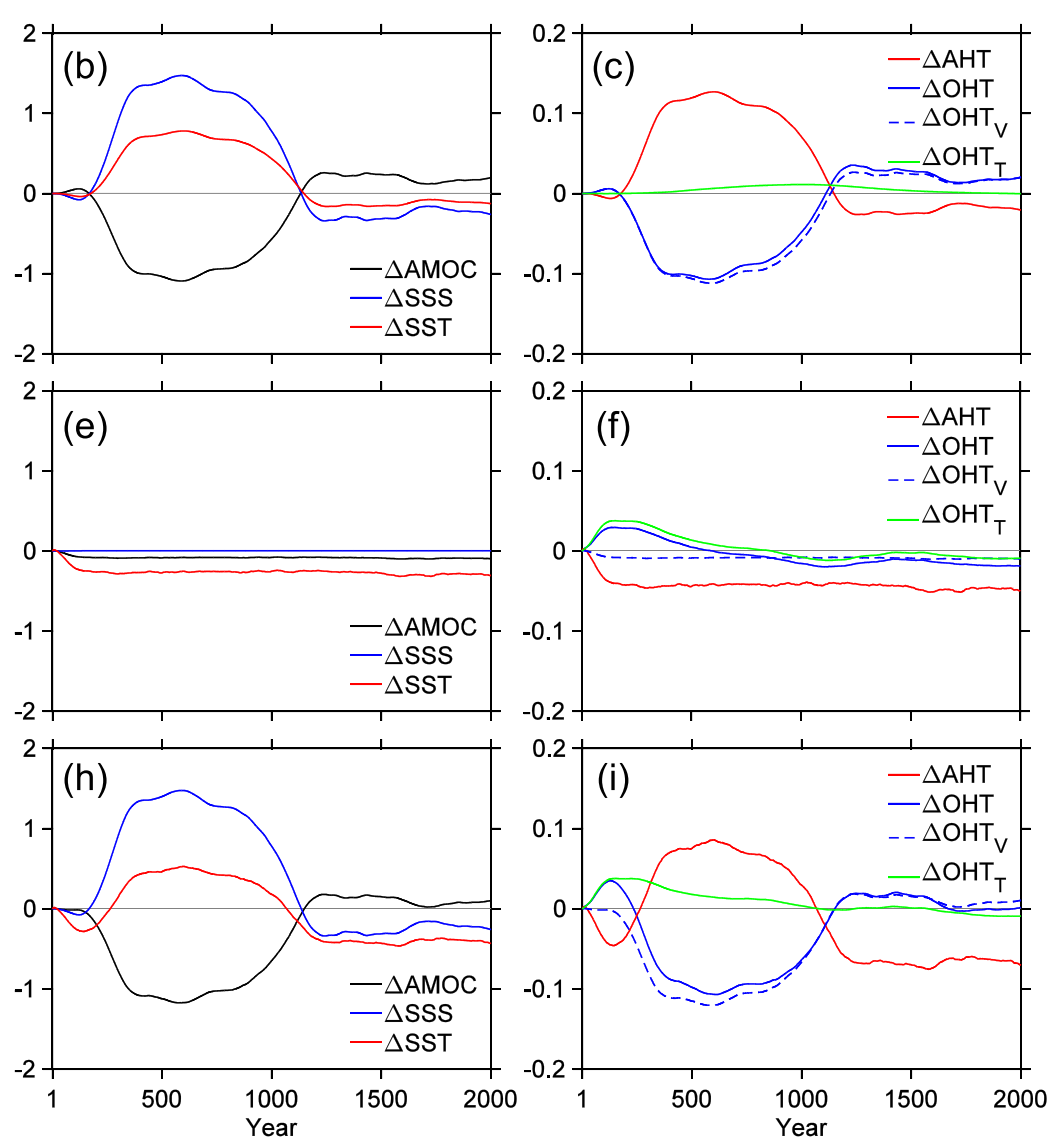
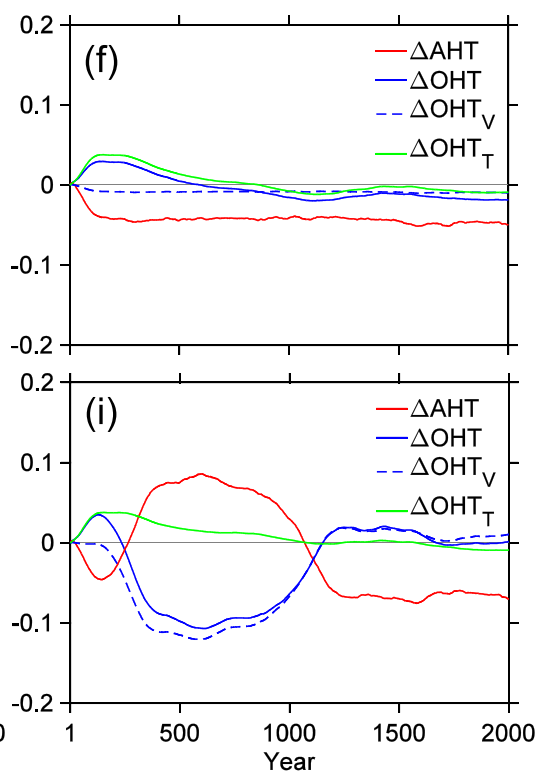

FIG. 11. Climate changes in the box model forced by freshwater and radiation fluxes obtained from CESM-CO2. (a),(d),(g) Changes in SST and SSS are plotted, (b),(e),(h) changes in the AMOC (black; Sv), meridional SST gradient (red; ${ }^{\circ} \mathrm{C}$ ), and meridional SSS gradient (blue; psu) are plotted, and (c),(f),(i) changes in AHT (red) and OHT (blue) in which the total OHT change is further decomposed into changes due to circulation (dashed blue) and stratification (green) (PW); (a)-(c) for Box-FW, (d)-(f) for Box-CO2, and (g)-(i) for Box-FW$\mathrm{CO} 2$. The local climate feedbacks used in Box-FW are $-B_{1}=-0.7$ and $B_{2}=0.0$, based on the LW feedback value averaged over stage-II (Figs. 10e,f).

Although in a warming climate, the Earth system gains additional energy because of the greenhouse effect, and the prerequisites to the $\mathrm{BJC}$ occurrence appear to be violated (Bjerknes 1964), the BJC can still occur because of the dominant role of the freshwater effect on the ocean thermohaline circulation. This is seen in CESM$\mathrm{CO} 2$, where the $\mathrm{BJC}$ is clear during the transient period of global warming. The sea ice melting in the polar ocean provides the freshwater flux to the North Atlantic, controlling the change of the AMOC, which ultimately results in opposite changes in OHT and AHT, that is, resulting in the $\mathrm{BJC}$ during the transient period of global warming. The mechanism of the $\mathrm{BJC}$ during this period is similar to that from freshwater hosing in the North Atlantic (Yang et al. 2013, 2017). An important implication of this study is that under the present-day global warming, we still expect that the BJC plays a stabilizing role in containing Earth's climate shift, as long as there is plenty of sea ice (or continental ice) to melt (Jungclaus and Koenigk 2010; Outten and Esau 2017). The change in hydrological cycle appears to cool the global surface temperature, slowing down the temperature rising in a warming world.

The role of freshwater in the $\mathrm{BJC}$ was emphasized in this work. Since it is difficult to separate the freshwater effect from the heating effect in the CESM-CO2 experiment, a simple coupled box model was used to understand freshwater's role in a warming climate. The freshwater change in the high latitudes plays a critical role in the BJC occurrence. Under heating-only perturbation, the $\mathrm{BJC}$ is unclear. In a warming climate, whether or not the freshwater effect can dominate over the heating effect in determining the thermohaline circulation is sensitive to the local climate feedback and the magnitude of external heating. Fortunately, under the doubled $\mathrm{CO}_{2}$ scenario, freshwater effect would still dominate the change of thermohaline circulation during the transient period of global warming. 
The BJC would still occur, but could become invalid, because the competing roles of freshwater and heating effects, as well as the climate feedbacks, can vary with time.

In a warming climate, although it is difficult to realize, the individual roles of freshwater and heating in changing Earth's energy balance and atmosphereocean circulations need to be identified in a complex climate system. This is necessary to reasonably assess the consequences of increasing greenhouse gases. We are working on quantifying the roles of freshwater and heating in global climate change intensely. In this current work, a fundamental concept was obtained that the freshwater change appears to have a stabilizing effect on the global climate change. It acts like a "brake" to at least slow down the SAT rising. This highlights the importance in understanding the change of the global hydrological cycle under global warming (Drijfhout et al. 2012; Bintanja and Selten 2014). One implication of our work is that the AMOC change under global warming depends on the change in the global hydrological cycle, instead of radiation balance. In Fig. 1c, we show clearly the recovery of the AMOC in about 1000 years in the doubled $\mathrm{CO}_{2}$ situation. The mechanism of the AMOC recovery remains unclear, and will be the subject of future study. Identifying the individual role of freshwater in a warming climate is critical to our understanding of the mechanism of AMOC change, and more importantly, to our understanding of the changes in global atmosphere-ocean circulations and climate variability at different time scales, and to ultimately making reliable predictions of future climate change. Of course, freshwater change may be only one part of a much larger puzzle causing the thermohaline circulation change. Ocean mixing, diffusion and convection related to surface buoyance change, wind-driven upwelling and downwelling, and other features could all play important roles.

Finally, our models have some limitations. First, applying results from a coupled box model to a fully coupled climate model may be problematic since the climate model has many components and there may be strong nonlinear interaction among these components. Second, the link between the AHT and the extratropical storm-track activities may not hold in some climate models. Third, the BJC in different coupled models may be different, since the hydrological cycle and the processes related to sea ice can be different. We will try to reproduce the results in this work using other climate models in the near future. Fourth, applying the findings in climate models to the real world is challenging.
Acknowledgments. This work is jointly supported by the National Key Research and Development Program of China (2016YFA0601802) and the National Nature Science Foundation of China (41725021 and 41376007). All experiments were performed on the supercomputer at the Laboratory for Climate and Ocean-Atmosphere Studies (LaCOAS) of Peking University.

\section{APPENDIX}

\section{A Coupled Box Model}

The coupled box model consists of a 2-box atmosphere and a 4-box ocean (Fig. A1). This box model was used in our previous studies aimed at understanding the fundamental mechanism of BJC (Yang et al. 2016; Zhao et al. 2016). The atmosphere is assumed to be always in quasi equilibrium with the surface ocean. The ocean model was based on Stommel (1961) and further developed in many studies (e.g., Marotzke 1990; Huang et al. 1992; NSM94; Tziperman et al. 1994; MS95). A detailed description of the box model can be found in Yang et al. (2016). The temperature and salinity equations for the surface ocean box are

$$
\begin{gathered}
\dot{T}_{1}=\frac{1}{\epsilon c \rho_{0} D_{1}}\left[\left(A_{1}-B_{1} T_{1}\right)+\chi\left(T_{2}-T_{1}\right)\right]+q\left(T_{2}-T_{1}\right), \\
\dot{T}_{2}=\frac{1}{\epsilon c \rho_{0} D_{1}}\left[\left(A_{2}-B_{2} T_{2}\right)-\chi\left(T_{2}-T_{1}\right)\right]+q\left(T_{4}-T_{2}\right), \\
\dot{S}_{1}=-\frac{S_{0}}{\epsilon_{w} D_{1}} \gamma\left(T_{2}-T_{1}\right)+q\left(S_{2}-S_{1}\right), \quad \text { and } \\
\dot{S}_{2}=+\frac{S_{0}}{\epsilon_{w} D_{1}} \gamma\left(T_{2}-T_{1}\right)+q\left(S_{4}-S_{2}\right),
\end{gathered}
$$

where $A_{1}$ and $A_{2}$ are net incoming radiation $\left(\mathrm{W} \mathrm{m}^{-2}\right)$ in the extratropics and tropics, respectively; $B_{1}$ and $B_{2}$ are climate feedback parameters in the extratropics and tropics, respectively; $\chi$ and $\gamma$ are the efficiencies of atmosphere heat and moisture transports, respectively; $c$ is the seawater specific heat capacity; $\rho_{0}$ is seawater density; and $S_{0}$ is a constant reference salinity. The variable $D_{1}$ is the depth of upper-ocean box. The variable $\epsilon$ indicates relative ocean coverage in both extratropical and tropical areas. The variable $\epsilon_{w}$ is similar to $\epsilon$, but includes the influence of river runoff on the oceanic freshwater budget, so $\epsilon_{w}>\epsilon$. The variable $q$ is the strength of the meridional mass transport, which is determined by both meridional temperature contrast $\left(T_{2}-T_{1}\right)$ and salinity contrast $\left(S_{2}-S_{1}\right)$. Variables $T_{4}$ 


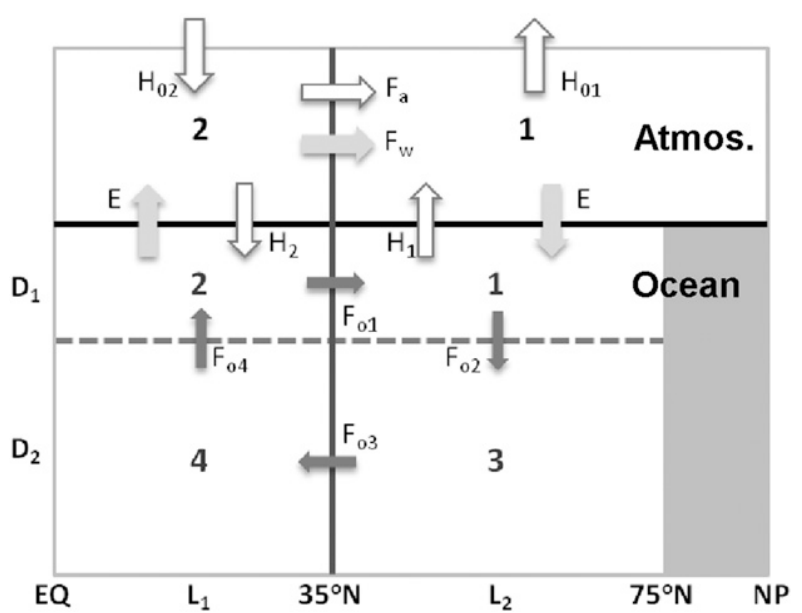

FIG. A1. Schematic plot of the coupled box model. Boxes 1 and 3 represent the upper and lower layers of the extratropical ocean, respectively; and boxes 2 and 4 represent the upper and lower layers of the tropical ocean, respectively. Variables $D_{1}$ and $D_{2}$ are the depths of upper and lower ocean layers, respectively; $L_{1}$ and $L_{2}$ are the meridional scales of the tropical and extratropical boxes, respectively; $H_{1}$ and $H_{2}$ are the ocean heat gains through the sea surface in the extratropics and tropics, respectively; $H_{01}$ and $H_{02}$ are the net energy gains at the TOA in the extratropics and tropics, respectively; $E$ is the net freshwater loss in the tropics, or the net freshwater gain in the extratropics; $F_{a}$ is the meridional atmosphere energy transport; $F_{w}$ is the meridional atmosphere moisture transport; and $F_{\mathrm{o} 1}-F_{\mathrm{o} 4}$ illustrate qualitatively the heat transports among different boxes. This figure is adapted from Fig. 1 of Yang et al. (2016).

and $S_{4}$ are the temperature and salinity of the lower tropical ocean, respectively. For simplicity, the formulas of $q, T_{4}$, and $S_{4}$ are not shown here. Readers can read Yang et al. (2016) for details. All parameters used in this study are listed in Table A1.

Under the circumstance of energy conservation, the equilibrium BJC ratio $C_{R}$ can be derived. Since detailed derivation can be found in Yang et al. (2016), it is simply shown here:

$$
C_{R} \equiv \frac{\Delta F_{a}}{\Delta F_{o}}=-\frac{1}{1+B_{1} B_{2} /\left[\left(B_{1}+B_{2}\right) \chi\right]} .
$$

Equation (A5) states that equilibrium $C_{R}$ is determined only by the intrinsic parameters of the climate system: the local climate feedback parameter $B_{i}$ and the AHT coefficient $\chi$. The mean temperature, salinity, and meridional heat transport, as well as their changes, do not affect $C_{R}$ in an energy conservation system. Therefore, the BJC can be thought of as an intrinsic mode of the climate system.

To understand the BJC under global warming, perturbation experiments are performed. The first box model experiment is a freshwater perturbation experiment (Box-FW; Table 1), with the freshwater added to the salinity equation of the extratropical ocean box [Eq. (A3)] as follows:

$$
F_{\mathrm{fw}}=F_{\mathrm{fw}}(t) .
$$

The term $F_{\text {fw }}(t)$ can be in any form. In this work, it uses the SSS anomaly from Fig. 6a. This experiment can qualitatively simulate the gradual sea ice melting in a warming climate. In the coupled box model, freshwater hosing to the ocean does not change the total energy of the system. This experiment is similar to that examined in Yang et al. (2016).

The second box model experiment is a heat-only perturbation experiment (Box-CO2; Table 1) in which an external heating is added to the temperature equations for both tropical and extratropical ocean surfaces [Eqs. (A1) and (A2)] as follows:

$$
F_{\mathrm{ht}}=F_{\mathrm{ht}}(t) .
$$

The term $F_{\mathrm{ht}}(t)$ can also be in any form. In this work, we use the net radiation flux at the TOA to replace $A-B T$ in Eqs. (A1) and (A2). This procedure mimics the

\begin{tabular}{|c|c|c|c|c|}
\hline Symbol & Physical meaning & Value & Reference & Note \\
\hline$A_{1}$ & Net incoming radiative flux at & Box 1: $-40 \mathrm{~W} \mathrm{~m}^{-2}$ & MS95 & - \\
\hline$A_{2}$ & & Box 2: $90 \mathrm{~W} \mathrm{~m}^{-2}$ & & \\
\hline$B_{1}$ & Local climate feedback parameter in & Box 1: $1.7 \mathrm{~W} \mathrm{~m}^{-2} \mathrm{~K}^{-1}$ & MS95 & - \\
\hline$B_{2}$ & & Box $2: 1.7 \mathrm{~W} \mathrm{~m}^{-2} \mathrm{~K}^{-1}$ & NSM94 & \\
\hline$c \rho_{0}$ & Heat capacity of a unit water volume & $4 \times 106 \mathrm{~J} \mathrm{~m}^{-3} \mathrm{~K}^{-1}$ & MS95 & - \\
\hline$D_{1}$ & Depth of upper and lower boxes & $400 \mathrm{~m}$ & - & - \\
\hline$S_{0}$ & Reference salinity & $35.0 \mathrm{psu}$ & MS95 & - \\
\hline$\epsilon$ & Ratio of ocean area & 0.2 & MS95 & Atlantic sector \\
\hline$\epsilon_{w}$ & Ratio of ocean and catchment area & 0.3 & MS95 & - \\
\hline$\gamma$ & Atmosphere moisture transport efficiency & $1.2 \times 10^{-10} \mathrm{~m} \mathrm{~s}^{-1} \mathrm{~K}^{-1}$ & MS95 & Factor of $1-3$ \\
\hline$x$ & Atmosphere heat transport efficiency & $1.3 \mathrm{~W} \mathrm{~m}^{-2} \mathrm{~K}^{-1}$ & MS95 & - \\
\hline
\end{tabular}
CESM-CO2 experiment. Note that such heating will

TABLE A1. Parameters used in this study, which are the same as those in Yang et al. (2016). 
cause an energy imbalance both globally and locally. Whether the BJC is still valid in this case is one of the questions to be explored in this study.

The third box model experiment is performed by simultaneously imposing heating and freshwater on the system (Box-FW-CO2; Table 1), that is, Eqs. (A6) and (A7) are applied at the same time. The combined effect can thus be assessed, and the relative contributions to the thermohaline circulation and MHT can be quantified. The standard parameters used in these experiments are listed in Table A1.

\section{REFERENCES}

Bintanja, R., and F. M. Selten, 2014: Future increases in Arctic precipitation linked to local evaporation and sea-ice retreat. Nature, 509, 479-482, https://doi.org/10.1038/nature13259.

Bjerknes, J., 1964: Atlantic air-sea interaction. Advances in Geophysics, Vol. 10, Academic Press, 1-82, https://doi.org/10.1016/ S0065-2687(08)60005-9.

Budyko, M. I., 1969: The effect of solar radiation variations on the climate of the earth. Tellus, 21(5), 611-619, https://doi.org/ 10.3402/tellusa.v21i5.10109.

Cheng, W., C. M. Bitz, and J. C. H. Chiang, 2013: Adjustment of the global climate to an abrupt slowdown of the Atlantic Meridional overturning circulation. Ocean Circulation: Mechanisms and Impacts-Past and Future Changes of Meridional Overturning, Geophys. Monogr., Vol. 173, Amer. Geophys. Union, 295-313.

Dai, H., H. Yang, and J. Yin, 2017: Roles of energy conservation and climate feedback in Bjerknes compensation: A coupled modeling study. Climate Dyn., 49, 1513-1529, https://doi.org/ 10.1007/s00382-016-3386-y.

Drijfhout, S., 2015: Competition between global warming and an abrupt collapse of the AMOC in Earth's energy imbalance. Sci. Rep., 5, 14877, https://doi.org/10.1038/ srep14877.

, G. J. Van Oldenborgh, and A. Cimatoribus, 2012: Is a decline of AMOC causing the warming hole above the North Atlantic in observed and modeled warming patterns? J. Climate, 25, 8373-8379, https://doi.org/10.1175/JCLI-D-12-00490.1.

Huang, R. X., J. R. Luyten, and H. M. Stommel, 1992: Multiple equilibrium states in combined thermal and saline circulation. J. Phys. Oceanogr., 22, 231-246, https://doi.org/10.1175/ 1520-0485(1992)022<0231:MESICT >2.0.CO;2.

Hunke, E. C., and W. H. Lipscomb, 2008: CICE: The Los Alamos Sea Ice Model, documentation and software user's manual, version 4.0. Los Alamos National Laboratory Tech. Rep. LA-CC-06-012, $52 \mathrm{pp}$.

Jungclaus, J. H., and T. Koenigk, 2010: Low-frequency variability of the Arctic climate: The role of oceanic and atmospheric heat transport variations. Climate Dyn., 34, 265-279, https:// doi.org/10.1007/s00382-009-0569-9.

Kang, S. M., I. M. Held, D. M. W. Frierson, and M. Zhao, 2008: The response of the ITCZ to extratropical thermal forcing: Idealized slab-ocean experiments with a GCM. J. Climate, 21, 35213532, https://doi.org/10.1175/2007JCLI2146.1.

- D. M. W. Frierson, and I. M. Held, 2009: The tropical response to extratropical thermal forcing in an idealized GCM: The importance of radiative feedbacks and convective parameterization. J. Atmos. Sci., 66, 2812-2827, https:// doi.org/10.1175/2009JAS2924.1.

Knutti, R., J. Flückiger, T. F. Stocker, and A. Timmermann, 2004: Strong hemispheric coupling of glacial climate through freshwater discharge and ocean circulation. Nature, 430, 851856, https://doi.org/10.1038/nature02786.

Langen, P. L., and V. A. Alexeev, 2007: Polar amplification as a preferred response in an idealized aquaplanet GCM. Climate Dyn., 29, 305-317, https://doi.org/10.1007/s00382-006-0221-x.

Lawrence, D. M., K. W. Oleson, M. G. Flanner, C. G. Fletcher, P. J. Lawrence, S. Levis, S. C. Swenson, and G. B. Bonan, 2012: The CCSM4 land simulation, 1850-2005: Assessment of surface climate and new capabilities. J. Climate, 25, 2240-2260, https://doi.org/10.1175/JCLI-D-11-00103.1.

Lindzen, R. S., and B. Farrell, 1977: Some realistic modifications of simple climate models. J. Atmos. Sci., 34, 1487-1501, https:// doi.org/10.1175/1520-0469(1977)034<1487:SRMOSC > 2.0.CO;2.

Liu, Z., H. Yang, C. He, and Y. Zhao, 2016: A theory for Bjerknes compensation: The role of climate feedback. J. Climate, 29, 191-208, https://doi.org/10.1175/JCLI-D-15-0227.1.

Manabe, S., and R. J. Stouffer, 1995: Simulation of abrupt climate change induced by freshwater input to the North Atlantic Ocean. Nature, 378, 165-167, https://doi.org/10.1038/378165a0.

Marotzke, J., 1990: Instabilities and multiple equilibria of the thermohaline circulation. Ph.D. thesis, Institut für Meereskund, University of Kiel, $126 \mathrm{pp}$.

- , and P. H. Stone, 1995: Atmospheric transports, the thermohaline circulation, and flux adjustments in a simple coupled model. J. Phys. Oceanogr., 25, 1350-1364, https://doi.org/ 10.1175/1520-0485(1995)025<1350:ATTTCA > 2.0.CO;2.

Nakamura, M., P. H. Stone, and J. Marotzke, 1994: Destabilization of the thermohaline circulation by atmospheric eddy transports. J. Climate, 7, 1870-1882, https://doi.org/ 10.1175/1520-0442(1994)007<1870:DOTTCB >2.0.CO;2.

North, G. R., 1975: Theory of energy-balance climate models. J. Atmos. Sci., 32, 2033-2043, https://doi.org/10.1175/ 1520-0469(1975)032<2033:TOEBCM >2.0.CO;2.

1984: The small ice cap instability in diffusive climate models. J. Atmos. Sci., 41, 3390-3395, https://doi.org/10.1175/ 1520-0469(1984)041<3390:TSICII > 2.0.CO;2.

Outten, S., and I. Esau, 2017: Bjerknes compensation in the Bergen Climate Model. Climate Dyn., 49, 2249-2260, https://doi.org/ 10.1007/s00382-016-3447-2.

Park, S., C. S. Bretherton, and P. J. Rasch, 2014: Integrating cloud processes in the Community Atmosphere Model, version 5. J. Climate, 27, 6821-6856, https://doi.org/10.1175/ JCLI-D-14-00087.1.

Rose, B. E. J., and D. Ferreira, 2013: Ocean heat transport and water vapor greenhouse in a warm equable climate: A new look at the low gradient paradox. J. Climate, 26, 2117-2136, https://doi.org/10.1175/JCLI-D-11-00547.1.

Seo, J., S. M. Kang, and D. M. W. Frierson, 2014: Sensitivity of intertropical convergence zone movement to the latitudinal position of thermal forcing. J. Climate, 27, 3035-3042, https:// doi.org/10.1175/JCLI-D-13-00691.1.

Sévellec, F., A. V. Fedorov, and W. Liu, 2017: Arctic sea-ice decline weakens the Atlantic meridional overturning circulation. Nat. Climate Change, 7, 604-610, https://doi.org/ 10.1038/nclimate3353.

Shaffrey, L., and R. Sutton, 2006: Bjerknes compensation and the decadal variability of the energy transports in a coupled climate model. J. Climate, 19, 1167-1181, https://doi.org/10.1175/ JCLI3652.1. 
Smith, R., and Coauthors, 2010: The Parallel Ocean Program (POP) reference manual. Los Alamos National Laboratory Tech. Rep. LAUR-10-01853, 141 pp.

Stommel, H., 1961: Thermohaline convection with two stable regimes of flow. Tellus, 13 (2), 224-230, https://doi.org/10.3402/ tellusa.v13i2.9491.

Stone, P. H., and M.-S. Yao, 1990: Development of a twodimensional zonally averaged statistical-dynamical model. Part III: The parameterization of the eddy fluxes of heat and moisture. J. Climate, 3, 726-740, https://doi.org/10.1175/ 1520-0442(1990)003<0726:DOATDZ>2.0.CO;2.

Stouffer, R. J., D. Seidov, and B. J. Haupt, 2007: Climate response to external sources of freshwater: North Atlantic versus the Southern Ocean. J. Climate, 20, 436-448, https://doi.org/ 10.1175/JCLI4015.1.

Trenberth, K. E., and J. M. Caron, 2001: Estimates of meridional atmosphere and ocean heat transports. J. Climate, 14, 3433-3443, https://doi.org/10.1175/1520-0442(2001)014<3433: EOMAAO $>2.0 . \mathrm{CO} ; 2$

Tziperman, E., J. R. Toggweiler, K. Bryan, and Y. Feliks, 1994: Instability of the thermohaline circulation with respect to mixed boundary conditions: Is it really a problem for realistic models? J. Phys. Oceanogr., 24, 217-232, https://doi.org/ 10.1175/1520-0485(1994)024<0217:IOTTCW > 2.0.CO;2.

van der Swaluw, E., S. S. Drijfhout, and W. Hazeleger, 2007: Bjerknes compensation at high northern latitudes: The ocean forcing the atmosphere. J. Climate, 20, 6023-6032, https:// doi.org/10.1175/2007JCLI1562.1.
Vellinga, M., and R. A. Wood, 2002: Global climatic impacts of a collapse of the Atlantic thermohaline circulation. Climatic Change, 54, 251-267, https://doi.org/10.1023/A:1016168827653.

— , and P. Wu, 2008: Relations between northward ocean and atmosphere energy transports in a coupled climate model. J. Climate, 21, 561-575, https://doi.org/10.1175/2007JCLI1754.1.

Woollings, T., J. M. Gregory, J. G. Pinto, M. Reyers, and D. J. Brayshaw, 2012: Response of the North Atlantic storm track to climate change shaped by ocean-atmosphere coupling. Nat. Geosci., 5, 313-317, https://doi.org/10.1038/ngeo1438.

Yang, H., and H. Dai, 2015: Effect of wind forcing on the meridional heat transport in a coupled climate model: Equilibrium response. Climate Dyn., 45, 1451-1470, https://doi.org/10.1007/s00382-014-2393-0.

_ - Y. Wang, and Z. Liu, 2013: A modelling study of the Bjerknes compensation in the meridional heat transport in a freshening ocean. Tellus, 65A, 18480, https://doi.org/10.3402/tellusa.v65i0.18480.

_- Y. Zhao, and Z. Liu, 2016: Understanding Bjerknes compensation in atmosphere and ocean heat transports using a coupled box model. J. Climate, 29, 2145-2160, https://doi.org/ 10.1175/JCLI-D-15-0281.1.

_ , Q. Wen, J. Yao, and Y. Wang, 2017: Bjerknes compensation in meridional heat transport under freshwater forcing and the role of climate feedback. J. Climate, 30, 5167-5185, https:// doi.org/10.1175/JCLI-D-16-0824.1.

Zhao, Y., H. Yang, and Z. Liu, 2016: Assessing Bjerknes compensation for climate variability and its time-scale dependence. J. Climate, 29, 5501-5512, https://doi.org/10.1175/ JCLI-D-15-0883.1. 